\title{
Tabagismo em diálogo: olhares sobre o discurso do Ministério da Saúde
}

Tobacco addiction in dialogue: insights of the discourse of the Ministry of Health

Tabaquismo en diálogo: miradas sobre el discurso del Ministerio de Salud

\section{Raphael Silva Souza Oliveira Carvalho}

- Mestre em Comunicação e Sociedade pelo Programa de Pós-Graduação em Comunicação da Universidade Federal de Juiz de Fora (UFJF)

- Especialista em Comunicação Empresarial e graduado em Comunicação Social pela UFJF

- Professor colaborador do Curso de Especialização em Comunicação Empresarial da UFJF

- Tem experiência em planejamento de comunicação organizacional, marketing, design e eventos

- Email: raphael.paradella@gmail.com

\section{Boanerges Balbino Lopes Filho}

- Doutor em Comunicação pela Universidade Federal do Rio de Janeiro (UFRJ)

- Mestre em Comunicação Social pela Universidade Metodista de São Paulo (Umesp)

- Bacharel em Comunicação Social - Jornalismo e Editoração

- Coordenador do Curso de Especialização em Comunicação Empresarial da Universidade Federal de Juiz de Fora (UFJF)

- Professor adjunto do Programa de Pós-Graduação em Comunicação e Sociedade da UFJF

- Presidente de conselho consultivo do Fórum Nacional de Professores de Jornalismo (FNPJ)

- Tem experiência em Jornalismo empresarial e científico, educação e relações públicas.

- E-mail: bblopes@globo.com 


\section{Resumo}

O tabagismo está em evidência. O debate sobre o tema envolve uma série de atores sociais, entre os quais as organizações, que se posicionam discursivamente como representação da própria identidade e da realidade. Por meio de estudos sobre identidade e estratégias de comunicação organizacional, além de revisões históricas, pudemos traçar uma contextualização para a análise de discurso. O trabalho busca por novos olhares sobre os textos institucionais do Ministério da Saúde.

PALAVRAS-CHAVE: COMUNICAÇÃO ORGANIZACIONAL •IDENTIDADES • DISCURSO • TABAGISMO • MINISTÉRIO DA SAÚDE

\section{Abstract}

Abuse of smoking is a theme that is in evidence. The debate involves a number of social players, among which we find organizations that position themselves discursively as a representation of their own identity and reality. By means of studies on identity, organizational communication strategies, as well as historical reviews, we were able to outline a context for the speech analysis. The study seeks new insights of the institutional texts of the Ministry of Health.

KEYWORDS: ORGANIZATIONAL COMMUNICATION • IDENTITIES • SPEECH • SMOKING • MINISTRY OF HEALTH

\section{Resumen}

El tabaquismo es un tema en evidencia. El debate implica una serie de actores sociales, entre los cuales las organizaciones, que se posicionan discursivamente como una representación de su propia identidad y realidad. A través de los estudios sobre la identidad y estrategias de comunicación organizacional, además de revisiones históricas, se pudo delinear una contextualización para el análisis de discurso. El trabajo proporciona nuevas perspectivas sobre los textos institucionales del Ministerio de Salud

PALABRAS CLAVE: COMUNICACIÓN ORGANIZACIONAL •IDENTIDADES • DISCURSO • TABAQUISMO • MINISTERIO DE SALUD 
$s$ processos comunicacionais que se integram ao ambiente organizacional podem ser admitidos das mais diversas maneiras. Na visão instrumental, a comunicação ganha contornos restritos à aplicação de ferramentas e aos estudos de envio e recepção de mensagens (informar). Por outro lado, preferimos compreender esses processos - assim como os estudos culturais e o interacionismo simbólico - como sendo formas de interação social.

Por essa ótica, o discurso se constitui em objeto de estudo. Mikhail Bakhtin (apud Dias, 2005) busca reforçar a noção de que a linguagem no meio social apenas pode ser compreendida por meio dos processos dialógicos. O ser humano é um ser social por natureza e interage pela linguagem - verbal ou não (Berger; Luckman, 2007).

Erving Goffman (2008) utiliza as metáforas teatrais para sintetizar a capacidade humana de representar o ser por meio do discurso. O autor reforça que, ao perceber o contexto em que se insere - a realidade cultural -, o ser humano se posiciona politicamente diante de tal cenário, encarna personagens (modulação discursiva), para que possa se ambientar e encontrar seu lugar no enredo. Pelo discurso que profere sobre a própria identidade é que se representa no meio social. Zygmunt Bauman (2008) apresenta as formas de consumo como sendo projeções públicas da identidade do ser. Aquilo que se consome ou se pode consumir, física e simbolicamente, coloca o indivíduo em determinada posição perante a sociedade e se incorpora à noção de identidade.

A comunicação enquanto articuladora discursiva configura uma representação estratégica da organização. O que alguns autores conceituam como sendo a projeção de uma imagem se manifesta aqui como uma perspectiva intencional sobre a representação personificada da organização no meio social no qual ela está inserida.

Nesse sentido, é pertinente lembrarmos-nos dos clássicos pensamentos de Platão e Aristóteles, quando se referem à retórica. A arte da persuasão por meio do discurso, entre muitas outras características, acaba por produzir uma representação do ser, mas também impõe determinadas características aos componentes da plateia. Na visão moderna de Stuart Hall (2002), a representação da identidade constrói paradigmas sobre os que fazem parte dessa realidade e os que se encontram alheios a isso (identidade versus diferença).

Ao estabelecer laços de relacionamento, a comunicação organizacional procura gerar o que ainda conceituamos como sendo a "personificação institucional", conceito desenvolvido em dissertação de mestrado (Carvalho, 2012). Em outras palavras, busca-se caracterizar a organização como um personagem da vida social, dotado de capacidades físicas, relacionais, intelectuais e discursivas, um ente que, pelo próprio fato de existir, deve manter interlocução com outros atores.

Ivone de Oliveira e Carine de Paula (2008) postulam como condição básica da comunicação no âmbito das organizações a responsabilidade pela geração de sentidos e, portanto, de valorações 
simbólicas. É essa construção de valores simbólicos - relacionados à cultura - agregados ao discurso que se fazem instrumentos para a promoção de identificações (mobilizações) ou não. São essas as perspectivas que se exploram no presente estudo, baseado em parte da pesquisa desenvolvida como dissertação de mestrado no Programa de Pós-Graduação em Comunicação da Universidade Federal de Juiz de Fora por um dos autores (Carvalho, 2012).

\section{TABAGISMO EM DISCUSSÃO}

As narrativas sobre o consumo do tabaco não são algo recente. Estudiosos da história do cigarro afirmam que as folhas de tabaco faziam parte das culturas ameríndias. Os ritos de fumo ou mascagem da planta se configuravam como o momento sublime no qual os pagés, xamãs ou caciques se diziam incorporados por espíritos divinos da cura, da prosperidade, da sexualidade e da fertilidade. Divindades ganhavam voz nas tribos por meio dos discursos de poder, em meio a ritos culturalmente estabelecidos. Somente essas figuras seriam capazes de trazer a realidade desejada.

Segundo registros feitos por Steve Luck (2008, p. 12), as grandes navegações dos séculos XV e XVI contribuíram decisivamente para a propagação da cultura do fumo no contexto mundial. Diz ele que

[a] referência às folhas de tabaco secas descreve o primeiro encontro europeu com a planta. Embora Colombo, muito agradecido, tenha aceitado os presentes - percebendo o significado da honra que a tribo local tinha dado a ele - ele próprio estava menos impressionado. (...) Tradicionalmente, o primeiro homem creditado com a introdução do costume de fumar para a Europa foi Rodrigo de Jerez, que tinha acompanhado Colombo em sua primeira viagem ao Novo Mundo. ${ }^{1}$

As batalhas pela colonização da América promoveram uma intensa disputa pelo intercâmbio de conhecimentos e hábitos de vida entre os países europeus e as localidades "encontradas do Novo Mundo". Os mares se tornaram o lugar ideal para o tráfico de informações e produtos, entre os quais o tabaco. Os espanhóis foram os pioneiros da comercialização e da transmissão dos valores da cultura do fumo. Mas logo ganharam a concorrência de outros países, assim como de marinheiros e piratas. Para evitar isso, o rei Felipe II proibiu que as colônias espanholas plantassem fumo, tendo sido liberada apenas a Colômbia, que exportava o produto exclusivamente para a cidade de Sevilha.

\footnotetext{
1 Tradução nossa.
} 
Essa decisão obrigou os demais países a buscar outras fontes da planta. Na mesma época surgiu a primeira iniciativa antitabagista. As crenças indígenas sinalizavam para o "mundo civilizado" a adoção de posturas pagãs. A Igreja se colocava discursivamente contra tais posturas, invocando a dicotomia entre o sagrado e o profano, por volta de 1604. Essa visão ganhou ainda mais força com a declaração do rei inglês Jaime I, de que fumar tabaco era algo "depreciável" (Boeira, 2002).

Dando um salto na história, após a consolidação da produção norte-americana e britânica em 1881, com a invenção e o aprimoramento da máquina de produzir cigarros em escala, grandes conglomerados industriais de tabaco ganhavam relevância como um dos mercados mundiais mais lucrativos. Ao mesmo tempo, as ciências da saúde começavam a ampliar as pesquisas que apontavam para os males do consumo de cigarros e derivados (Boeira; Johns, 2007), garantindo ao século XX uma arena para intensas discussões sobre essa questão.

Grandes empresas produtoras de tabaco passaram a se consolidar em todo o mundo, destacando-se a British American Tabacco (BAT). Os esforços eram no sentido de conquistar maior popularização das marcas, bem como a segmentação da produção e o aprimoramento dos processos industriais. Nos primeiros vinte anos do século passado multiplicaram-se também as estratégias dos antitabagistas, que conseguiram a aprovação das primeiras leis de combate ao consumo e de diminuição da produção no Estados Unidos e na Europa.

As indústrias passaram a adotar estratégias diferenciadas para burlar as leis: a venda dos componentes do cigarro isoladamente, o tráfico ilegal e a criação dos filtros para os cigarros. Esta última providência, ao mesmo tempo em que se tornou uma novidade para aquecer as vendas, se transformou em uma poderosa arma discursiva, à medida em que podia ser interpretada como uma preocupação das organizações com a saúde dos consumidores, tendo em vista que os filtros visam à diminuição dos teores químicos do produto. Esse conjunto de estratégias fez com que grande parte as leis aprovadas fossem abolidas já na década de 1920.

A pressão imposta pelo movimento antitabagista e pela política acabou forçando as produtoras passem a adotarem novos posicionamentos sociais e novas táticas. Uma das áreas mais contempladas pelas mudanças foi a da comunicação. Para referenciar os tópicos abordados pelas organizações, lembremos aqui a metáfora da "guerra"2 (Tom Clancy, apud Sardinha, 2007, p. 98). Segundo Sérgio Boeira e Paula Johns (2007, p.4-5), as organizações

\footnotetext{
${ }^{2}$ Diferente do jogo, que pressupõe uma disputa sadia, sem destruição à equipe derrotada, na guerra dois ou mais lados e enfrentam. A intenção é aniquilar um ao outro. "A disputa é uma guerra ou uma batalha, desonesta e violenta" (Sardinha, 2007, p. 103). "Para vencer, a empresa deve possuir uma estratégia, palavra muito próxima da metáfora da guerra, a fim de conquistar o mercado. O comportamento é agressivo, reflexo da luta pela sobrevivência e pela conquista de território" (Lopes Filho et. al., 2010, p. 11).
} 
reagem de modo a intensificar estratégias de defesa de seu domínio (domain defense, ou seja, controle de informações vitais e busca de colaboração entre competidores tradicionais), estratégias de ataque (domain ofense, a busca de eficiência, acirrada competição nas áreas de inovação e segmentação dos públicos alvos) e, finalmente (ou simultaneamente), de criação de novos espaços (domain creation ou a diversificação dos investimentos em mercados externos, valorização da independência entre as empresas). No conjunto, essas diferentes esferas de ação estratégica requerem aprendizagem organizacional constante - organização flexível, criativa e incisiva -, muitos gastos com marketing (pesquisa de mercado e publicidade), atuação política junto a congressistas, órgãos públicos e mídia, de tal maneira que os valores de cooperação, competição e independência se constituem como núcleo das relações entre as empresas do setor.

As formas de comunicação adotadas acabaram mirando os aspectos que tangem à indústria cultural, como forma de inserir ainda mais o consumo de tabaco na sociedade. $O$ cinema criou grandes ícones de Hollywood e a propaganda cunhou modelos de personalidade - a exemplo do Cowboy da Malboro, nos Estados Unidos. A segmentação das estratégias em relação aos diferentes públicos foram marcantes: homens (cultura masculina é antiga, muitas vezes ligada ao poder); mulheres (anos 1950: movimentos feministas); e jovens (anos 1970: senso de liberdade). Os produtos também seguiram essas tendências: para os homens, cigarros com teores mais elevados de nicotina; e para as mulheres, cigarros mais alongados e mais finos, com teor reduzido, por exemplo.

Por outro lado, passaram a ampliar-se as entidades antitabagistas, como organizações governamentais e não-governamentais, instituições de saúde, além de crescer o número de pesquisadores e cientistas dedicados a essa causa. Casos patológicos decorrentes do consumo de cigarros começaram a ganhar espaço na mídia a partir das décadas de 1970 e 1980. Na época, as articulações políticas ganharam dimensão mundial, por meio de discussões travadas pela Organização Mundial de Saúde. Surgiram as primeiras diretrizes de combate ao tabagismo e, por consequência, legislações mais específicas - em conjunto com o senso de "geração saúde". No Brasil, por exemplo, em junho de 1986, foi criado o Dia Nacional de Combate ao Fumo. No final da década de 1980 e inicio dos anos 1990, o país lançou o Programa Nacional de Controle do Tabagismo (restrições na comunicação, aumento de impostos, advertências sanitárias e regulação do consumo).

Sérgio Boeira (2002, p. 57) faz referência às contradições entre o aumento da produção mundial de cigarros e os movimentos antitabagistas. "Essas mudanças e características do setor sinalizam, a meu ver, um início de autoconfronto social, cultural e institucional dentro do paradigma da modernidade". O autor destaca o paradoxo diante do qual os governos mundiais se encontram: por um lado, eles têm como função a proteção da saúde dos indivíduos; por outro, o setor econômico ainda referencia o crescimento da indústria tabagista. A propósito, o Brasil, atualmente, 
é o segundo maior produtor e exportador de cigarros do mundo, segundo dados da International Tobacco Grower's Association (Itga, 2011), sendo bem alta sua arrecadação de impostos com o produto. "Saia justa" que persiste até os dias atuais...

Nos primeiros anos deste novo século ocorrem as maiores restrições às Indústrias produtoras de cigarros, intensificando-se as políticas públicas e crescendo o número de grupos de tratamento e educação antitabagista. Por outro lado, a indústria buscou alternativas como brindes, diversificação, saborização, diminuição de teores, novo design, entre outras iniciativas, que continuaram levando o cigarro a conquistar espaços entre os consumidores. Recentes leis regionais e municipais foram aprovadas para restringir o consumo de cigarros em locais públicos fechados ou semifechados. Essa decisão governamental forçou mais uma mudança na postura discursiva dos atores sociais envolvidos. A temática se torna cada vez mais evidente nos veículos de comunicação que externalizam a disputa discursiva em torno dessa questão.

\section{O DISCURSO DO MINISTÉRIO DA SAÚDE}

Para o presente estudo fizemos, inicialmente, uma revisão bibliográfica das visões sociológicas sobre as identidades envolvidas por um sistema cultural simbólico e discursivo do âmbito social. Em seguida, pesquisamos dados sobre a história do tabaco e as disputas travadas entre os movimentos antitabagistas e as indústrias tabagistas. Com esses passos buscamos embasar as possíveis relações entre os posicionamentos organizacionais assumidos em determinados contextos e as relações de poder discursivo no que tange ao tabagismo.

Em trabalho anterior (Carvalho; Lopes Filho, 2010), por meio de um processo de análise de discurso, procuramos detectar as nuances segundo as quais é possível construir determinadas representações da identidade do consumidor de cigarro e derivados, analisando o discurso institucional da Souza Cruz, detentora de algumas das marcas de cigarros mais conhecidas do Brasil. A pesquisa buscou referências sobre a identidade dos consumidores e a situação da saúde.

Tendo como base as teorias desenvolvidas por Bakhtin, todo discurso é por si dialógico e, à medida que sofre mudanças, fornece um novo cenário, exigindo também uma alteração no discurso do "segundo polo". É necessário compreender os cenários contextuais para que seja possível extrair os processos enunciativos ${ }^{3}$ do discurso, tendo em vista que esses processos se relacionam com os valores simbólicos vigentes na cultura em que o discurso se insere - o que justifica a revisão histórica feita anteriormente.

\footnotetext{
3 "Do nosso ponto de vista, aquilo que Bakhtin chama de contexto e situação adquire um outro estatuto: não se trata de atribuir à palavra um sentido em relação à situação de mundo ou a uma 'porção' da realidade. Trata-se, antes, de conceber a palavra na relação com os fatos de discurso, isto é, na relação com o interdiscurso, que comparece como espaço de memória na enunciação (da palavra). Assim, o centro organizador da enunciação estaria não no meio social que envolve o indivíduo, mas no fato de o indivíduo ocupar uma posição de sujeito em relação aos fatos de discurso" (Dias, 2005, p. 105).
} 
Compreendemos que as discussões sobre a questão do tabagismo envolvem uma série de atores sociais. Contudo, como recorte para a presente pesquisa, utilizamos os discursos do Ministério da Saúde, especificamente do Instituto Nacional do Câncer (Inca), órgão responsável pelo Programa de Controle do Tabagismo Brasileiro, disponibilizados em site oficial. Fizeram parte da amostra estudada os textos institucionais presentes em oito links disponibilizados pelo portal www.inca.gov.br/tabagismo, atendo-nos apenas aos recursos discursivos verbais e que constituem parte integrante do conteúdo "fixo" do website.

Sendo assim, nossa proposta foi no sentido de uma análise de discurso baseada nos mesmos preceitos utilizados para o estudo anterior sobre o discurso da Souza Cruz. Nosso intuito foi identificar de que formas os representantes do poder público se manifestam e se posicionam quanto a essas questões. Lembramos, mais uma vez, que este trabalho não permite obter respostas sobre a forma como os interlocutores recebem as mensagens. O objetivo é perceber como a identidade institucional do Ministério da Saúde é representada nos aspectos relativos ao tabagismo e como esse órgão procura delinear o consumidor de cigarros.

\section{O consumidor no discurso do ministério}

A construção de protótipos da identidade do receptor é uma característica inerente ao processo de comunicação. O conceito de audiência presumida, desenvolvido por Alfredo Vizeu (2005), mostra como o telejornalismo, ao construir o conteúdo, traduz uma série de características imaginadas sobre o perfil do público, tendo em vista aspectos culturais, lógicas de mercado e regras de redação. Por outro lado, as relações públicas imaginam os perfis dos públicos de relacionamento a partir de aspirações dos chamados stakeholders. Ao referenciar tais características, o processo de comunicação visa articular discursivamente (verbalmente ou não) formas de enunciação para atingir esses públicos. Sendo assim, acaba por delimitar que pessoas terão acesso ao processo comunicativo e quais ficarão de fora.

Dessa forma, nosso objetivo foi identificar os recursos discursivos adotados pelo Ministério da Saúde (MS) para conformar uma representação dos públicos, que dividimos em duas categorias: consumidores de informações e consumidores de produtos. Mesmo havendo certa ligação entre essas subcategorias, vemo-las como delimitações diferenciadas de públicos, em conformidade com as categorias de diálogo estabelecidas pela metodologia.

Para a primeira categoria o MS afirma, com base em acordos mundiais e legislações vigentes, o propósito de sua comunicação. A citação a seguir foi retirada da Convenção-Quadro para o Controle do Tabaco (CQCT) $)^{4}$ :

\footnotetext{
4 "É um instrumento legal, sob forma de um tratado internacional, no qual os países signatários (estados partes) concordam em empreender esforços para alcançar objetivos definidos previamente" (Inca, 2011).
} 
Regulamentação dos conteúdos e emissões dos produtos derivados do tabaco; divulgação de informações relativas a estes produtos; desenvolvimento de programas de educação e conscientização sobre os malefícios do tabagismo; proibição de publicidade, promoção e patrocínio; implementação de programas de tratamento da dependência da nicotina (Inca, 2011).

É comum no discurso do MS o objetivo de se posicionar quanto à restrição aos conteúdos informacionais. Expressões como controle, regulamentação, proibição, coordenação, padrões de controle, vigilância e restrição fazem parte frequentemente dos textos que visam à criação de uma espécie de barreira às informações inverídicas divulgadas pelas produtoras de cigarros. $O$ consumidor de informações se vê obrigado a seguir tais diretrizes e a buscar apenas os conteúdos indicados pelo MS.

As informações divulgadas pelo MS são, na maioria, embasadas pelos termos pesquisas, testes, estudos e documentos, que garantem certo respaldo de legitimidade discursiva. Contudo, é notória a utilização de termos científicos, como prevalência e epidemiologia, os quais, se facilitam a compreensão por parte dos estudiosos e dos mais escolarizados, dificultam o entendimento por outra parcela da população.

Além disso, o discurso da mídia - seja pelo cinema, pela teledramaturgia, por impressos ou pelo jornalismo - acaba por servir de base para o surgimento de novos modelos propagandísticos da cultura do tabaco:

[A maioria das pessoas] é influenciada pela publicidade maciça do cigarro nos meios de comunicação de massa que, apesar da Lei de Restrição da Propaganda de produtos derivados do tabaco (...), ainda têm forte influência no comportamento tanto dos jovens como dos adultos. Além disso, pais, professores ídolos e amigos também exercem grande influência (Inca, 2011).

Segundo o MS, os meios de comunicação "utiliza[m] a imagem de ídolos e modelos de comportamento de determinado público-alvo portando cigarros ou fumando-os, ou seja, [fazem] uma forma indireta de publicidade" (Inca, 2011).

Quanto à segunda categoria, os consumidores de produtos, existe a percepção de dois tipos claros de interlocutores: consumidores ativos e consumidores passivos. Podemos dizer sinteticamente, com base nos dados estatísticos, que os consumidores ativos se caracterizam por serem adultos ou jovens de ambos os gêneros, que têm quinze anos ou mais, fazem experimentação no período escolar, são dependentes de substâncias químicas, possuem considerável poder aquisitivo, têm na maioria até oito anos de formação acadêmica e constituem um terço da população. 
Contudo, os textos analisados apresentam as seguintes características metafóricas, que se manifestam como subtextos em construções enunciativas: cotidiano, saúde, mercado e vândalo. A metáfora do cotidiano se refere aos espaços de convivência social, podendo ser percebida em expressões como: o comportamento de fumar, consumo por dia, cognitivo-comportamental, casa, bares, escolas etc. Quanto às referências à saúde, percebemos discursos que remetem ao consumidor como paciente que se mostra dependente de tratamento médico, psicológico e de amparo de terapias medicamentosas ou alternativas.

O consumidor envolvido no campo mercadológico é visto como público-alvo, consumidor e em idade produtiva. Todas as referências apresentadas fazem com que os fumantes se aproximem negativamente de outros atores do debate público sobre o tabagismo: da indústria tabagista e do ambiente de trabalho (relação entre consumo e trabalho). Essa preocupação com o lado econômico está presente, também, como exemplo, na seguinte citação: "Quando as pessoas param de fumar, elas não deixam de consumir, apenas redirecionam seu dinheiro para a compra de outros bens e serviços" (Inca, 2011).

Outra forma de relacionamento diz respeito à perspectiva do vandalismo. O fumante é visto como capaz de provocar danos à alteridade e aos bens de outrem, ao expressar a identidade por meio do consumo, e por isso deve ser socialmente isolado. Aqui nos lembramos de Norberto Bobbio (1992), quando diz que, ao se conceder um direito a uma parcela da sociedade, poda-se o direito de outros. O texto do Ministério da Saúde cita a necessidade de retratar que o tabagismo não é bem aceito na sociedade, pelo fato de ser produtor de ar poluído.

Os fumantes passivos podem ser caracterizados como sendo adultos, jovens ou crianças não consumidores, que vivem expostos a riscos ao inalarem a fumaça dos cigarros provocada pelo tabagismo. A própria noção de alteridade traduz características que o texto silencia. Podemos aferir noções identitárias pelas descrições feitas dos consumidores ativos (a diferença evidencia a identidade). Assim sendo, o consumidor indireto é colocado como submisso às decisões do direto, ou seja, cabe ao consumidor final a responsabilidade e o dever de zelar ou não pela integridade do ambiente do qual os consumidores passivos são "obrigados" a partilhar.

\section{A saúde no discurso do ministério}

Em termos de saúde, o MS se manifesta socialmente como referência máxima no país, como não poderia deixar de ser. É um centro de incentivo à obtenção de informações, a pesquisas científicas e a políticas de promoção da saúde. Sendo assim, quais seriam as perspectivas sobre saúde desenvolvidas pelos recursos discursivos presentes do website sobre tabagismo e que são lançadas no debate social sobre a questão? 
Para iniciar a pesquisa, temos as perspectivas apontadas anteriormente ao nos referirmos ao consumidor, discorrendo sobre a metáfora da "saúde". Contudo, para o presente tópico lançamos mão das três perspectivas avaliadas no discurso da Souza Cruz, que também se apresentam nos textos estudados: cadeia produtiva, o ato de fumar e os riscos à saúde.

Na primeira categoria de análise, nos foi possível encontrar uma perspectiva alinhada às técnicas de gestão. Expressões como estratégias, objetivos, planos, produção, publicidade, consumidores, mercado, exportação e economia são exemplos disso. Há um direcionamento claro de que toda a cadeia produtiva é vista como meramente comercial, em um processo desumanizado. No decorrer da análise, estiveram presentes a relação entre a personificação dada à indústria e a outros atores da cadeia produtiva, dentre os quais sobressaem o produtor rural, o consumidor, órgãos legisladores,o mercado externo, a sociedade médica, a sociedade em geral etc.

Em todas essas instâncias destacam-se aspectos negativos: para o produtor rural, uma situação de "dependência" do plantio, danos à saúde e situação de dominação (Carvalho, 2011); os consumidores têm "danos" financeiros (em constante aumento graças à elevação dos tributos), de saúde, sociais e psicológicos; os órgãos legisladores se veem sob constante pressão quando se trata da aplicação jurídica de medidas, considerando as vantagens econômicas do tabagismo para o país, além das brechas nas legislações que favorecem o emplacamento de novas estratégias de atuação da indústria - ou seja, há uma diminuição da capacidade de exercer autoridade (socialmente concebida e idealizada); sociedade médica também sob pressão com relação ao desenvolvimento de pesquisas, grupos e técnicas mais apuradas para atuação e tratamento; a sociedade geral se vê à mercê da "poluição tabagística ambiental" que se apresenta "contra a saúde pública e o bem-estar da população" (Inca, 2011), sendo responsável pelo custeio de uma variedade de tratamentos e como "fator agravante da fome e da pobreza" (Inca, 2011).

Nesse sentido, ainda se destacam alguns pontos positivos para a economia: rentabilidade de impostos e posicionamento do comércio exterior. O Brasil é o maior exportador mundial de foIhas de tabaco, o quarto maior produtor de cigarros e arrecada centenas de milhões de reais em impostos anuais. São questões que colocam as autoridades antitabagistas diante de um "conflito", da "falta de consenso" e de uma "variedade de métodos", ou seja, de um discurso muitas vezes contraditório.

No que diz respeito à segunda categoria proposta (o ato de fumar), a pesquisa identificou três tópicos de destaque: processo de experimentação, representação social e processo de abandono da condição de consumidor. Expressões como desafio, quadro alarmante, dependência prematura e a construção frasal "a magnitude do fenômeno do tabagismo ultrapassa as questões específicas do biológico e traz consequências na vida social, cultural e econômica" (Inca, 2011) traduzem as perspectivas do discurso. 
A primeira categoria está baseada em pesquisas e estudos que investigam as causas da iniciação do consumo de cigarros e derivados do tabaco, apontando para uma maioria iniciante em período escolar e em faixa etária abaixo dos dezenove anos. Nesse sentido, a comunicação se apresenta como grande vilã, associada a um grande poder de manipulação psicológica nos jovens, aparecendo em expressões como promoção, marketing, propaganda, meios de comunicação de massa, divulgação e veiculados. Por influência das mídias, são disseminados valores simbólicos que se traduzem - segundo perspectiva do discurso - em exemplos a serem seguidos, associados ao tabagismo e estimuladores de condutas. Palavras como modelo, rebeldia, autoafirmação, liberdade, sucesso, beleza e aceitação social são direcionadas para a influência em prol de uma atitude psicocomportamental negativa.

Esse assunto também entra em contato com as perspectivas sobre a representação social do fumante, descrita a partir da criação de um mundo ilusório pela mídia. "A divulgação dessas ideias ao longo dos anos tomou o hábito de fumar um comportamento socialmente aceitável e até positivo" (Inca, 2011). Assim, é possível perceber que a identidade tabagista é mutável ao longo dos tempos e se torna uma construção social e compartilhada. Em vários momentos, encontramos expressões como essas que visam à negativização da representação dessa identidade marcada pelo consumo de derivados do tabaco, não apenas do produto. Há uma aparente tendência ao isolamento social do ser, enquanto este se manifesta por meio de tal hábito de consumo.

Essa transformação é retratada no texto pelas formas habituais de consumir. O derivado de tabaco que se consome (rapé, fumo de rolo, cachimbos, cigarros, cigarrilhas, charutos etc.) coloca o indivíduo em outras posições sociais, mesmo sendo essa apenas uma variação "comportamental" - tendo em vista que os problemas causados são os mesmos e as concentrações de substancias tóxicas não variam em relevância. Ou seja, tendo em vista o contexto de intensa regulação do tabagismo, notamos uma vontade de se construir um novo cenário idealizado pelas perspectivas de saúde pública ("mostrar que o tabagismo não é tão aceitável socialmente quanto parece"), cenário no qual o tabagista se torna um ser marginal. Para ser novamente tido como um agente ativo na vida social, o consumidor deve deixar essa vertente identitária.

Esse gancho nos leva a abordar a terceira subcategoria analítica: o processo de abandono, aqui relacionado com o paciente, o aluno e o autocontrolador. Quanto ao paciente, vê-se o consumidor como um doente, controlado, submetido a um tratamento, medicamentoso ou alternativo, fechado em modelos específicos e com condutas padronizadas e "sistematizadas. Para o aluno há planos de ação efetivados em ambientes escolares ou em conduta didática (orientações fornecidas pelo próprio site em termos de educação); expressões como fundamentação teórica, tradução, educação, conscientização e escolaridade são frequentes nos textos analisados; notamos também que a conscientização proposta acaba, em alguns casos, se limitando à descrição de condutas, doenças e componentes do tabaco com a utilização de termos técnicos. 
Quanto ao autocontrolador, a questão é colocada como se o próprio consumidor se tornasse responsável pela metodologia de cessação do consumo; flexões modais do discurso transformam construções frasais em espécies de dicas para os consumidores conquistarem o objetivo de parar de fumar - o desafio (metaforicamente visto como jogo, no qual se estipulam as regras básicas e se dão informações privilegiadas para maior eficiência e eficácia das estratégias traçadas pelo próprio jogador).

No que tange aos riscos à saúde, temos as seguintes perspectivas: composição, doenças e dados estatísticos. Em todos os casos encontramos expressões que dizem respeito à cessação do tabagismo como a única saída para a redução dos riscos à saúde, traduzida como esperança para os condenados ("a luz no fim do túnel”). Os elementos que compõem o tabaco e as doenças provocadas por eles são, em grande parte, tratados com linguagem científica e segundopadrões linguísticos de difícil acesso. Por outro lado, os dados estatísticos buscam esclarecer o cenário em que se encontram os tabagistas. Expressões como risco, pode e frequência caracterizam uma possibilidade, ou seja, ao mesmo tempo em que criam uma atmosfera de esperança geram o temor.

\section{CONSIDERAÇÕES FINAIS}

As mudanças contextuais e os novos posicionamentos político-discursivos estabelecidos pelos demais atores sociais envolvidos no debate público sobre o tabagismo implicam não apenas uma interlocução entre os discursos, mas também uma necessidade de nova articulação discursiva. Como se percebe claramente, os agentes ativos nas discussões estão presentes e dialogam com as perspectivas do MS. Há, por exemplo, uma intensa recorrência aos estudos e às pesquisas científicas, além de referência a outros discursos legitimados, objetivando apresentar a causa antitabagista como sendo um conglomerado de forças políticas. Os textos são pautados pela articulação discursiva da Souza Cruz e da indústria tabagista de modo geral, em constante tentativa de deslegitimação.

Por se tratar de uma instituição representante do poder público, o MS busca a legitimação muitas vezes por meio de legislações e programas, traduzindo uma espécie de enclausuramento do tabagista como consumidor, como ser marginalizado socialmente, tendo em vista que se condena não só o uso habitual dos derivados, como também o consumidor. Os dados estatísticos, que representam em primeira instância legitimadores discursivos, são geralmente acompanhados de expressões que se traduzem, ao mesmo tempo, em esperança de não se ser vítima de nenhum mal, mas também no temor de fazer parte dos números.

Os textos também direcionam para uma visão idealizada de uma realidade futura, na qual a sociedade viveria sem problemas de saúde advindos do tabagismo. Os recursos utilizados ten- 
tam mobilizar e inserir tal visão no ambiente social cotidiano, propondo uma mudança cultural construída ao longo da história, pela mídia e por outras questões, de que os derivados do tabaco são aceitos. Nesse sentido há uma negativização do papel social dos meios de comunicação, vistos como atores ativos do processo de construção da realidade enquanto propagadores de um imaginário coletivo favorável e de uma tentativa de regulação das formas de comunicação nesse sentido. A ideia do "bem maior" está presente em todo o texto por meio dos recursos sobre a coletividade.

Esses novos olhares sobre o discurso do MS nos permitem retirar importantes perspectivas sobre o cotidiano vigente e compreender um pouco mais a realidade em que vivemos. Além disso, levantam novos questionamentos que poderão alavancar as pesquisas realizadas no campo da comunicação - não apenas no âmbito das organizações - e em outros ambientes científicos nos quais o debate público sobre o tabagismo se encontra como grande lugar de sombra.

Para nós, o conteúdo deste trabalho nos leva a um próximo estágio, no qual serão propiciadas percepções dialógicas sobre o processo de construção discursiva dos atores envolvidos e de que maneiras estes se relacionam, por meio de sistemas comunicacionais, com outros atores sociais - ambiente de disputas pelo poder discursivo.

\section{REFERÊNCIAS}

BARROS, Dana Luz Pessoa de. Contribuições de Bakhtin às teorias do texto e do discurso. In: FARACO, Carlos A. et. al. Diálogos com Bakhtin. Curitiba: Ed. da UFPR, 2001. p. 21-42.

BAUMAN, Zygmunt Globalização: as consequências humanas. Trad. de Marcus Penchel. Rio de Janeiro: Jorge Zahar, 1999.

Vida para o consumo: a transformação das pessoas em mercadoria. Trad. de Carlos Medeiros. Rio de Janeiro: Jorge Zahar, 2008.

BERGER, Peter Ludwig; LUCKMAN, Thomas. A construção social da realidade: tratado de sociologia do conhecimento. Petrópolis: Vozes, 2007.

BOBBIO, Norberto. A era dos direitos. Trad. de Carlos Coutinho. Rio de Janeiro: Campus, 1992.

BOEIRA, Sérgio Luís. Atrás da cortina de fumaça: tabaco, tabagismo e meio ambiente. Estratégias da Indústria e dilemas da crítica. Itajaí: Ed. Univali, 2002.

BOEIRA, Sérgio Luís; JOHNS, Paula. Indústria de tabaco vs. Organização Mundial de Saúde: um confronto histórico entre redes sociais de stakeholders. Interthesis, Florianópolis, n. 4, p. 1-25, 2007. Disponível em: <http://www. periodicos.ufsc.br/ index.php/interthesis/article/view/895>. Acesso em: 13 jul. 2010. 
CARVALHO, Raphael Silva S. Oliveira. Discursos em cinzas: olhares sobre as representações identitárias de fumantes segundo discursos institucionais. Dissertação (Mestrado em Comunicação) - Universidade Federal de Juiz de Fora, 2012.

Folkcomunicação e comunicação organizacional: a Afubra como líder comunitária dos fumicultores brasileiros em busca de novas representações. In: CONFERÊNCIA BRASILEIRA DOS ESTUDOS DA FOLKCOMUNICAÇÃO, XIV, Juiz de Fora, 2011. Anais... São Paulo: Folkcom - Rede Brasileira de Estudos e Pesquisa em Folkcomunicação, 2011.

CARVALHO, Raphael Silva S. Oliveira LOPES FILHO, Boanerges B. É proibido fumar?: considerações sobre o posicionamento discursivo da Souza Cruz. In: CONGRESSO BRASILEIRO DE CIÊNCIAS DA COMUNICAÇÃO, XXXII,. Caxias do Sul (RS), 2010. Anais... São Paulo: Intercom, 2010.

DIAS, Luiz Francisco. Significação e forma linguística na visão de Bakhtin. In: BRAIT, Beth. Bakhtin: dialogismo e construção de sentido. Campinas (SP): Editora da Unicamp, 2005. p 99-107.

GOFFMAN, Erving. A representação do eu na vida cotidiana. Petrópolis: Vozes, 2008.

HALL, Stuart. Identidade cultural na pós-modernidade. Trad. De Tomaz Tadeu da Silva e Guacira Lopes Louro. 7. ed. Rio de Janeiro: DP\&A, 2002.

INCA - Instituto Nacional do Câncer. Tabagismo. Disponível em: <www.inca.gov.br/tabagismo>. Acesso em: fev. 2011.

ITGA. International Tobacco Grower's Association. Disponível em: <http://www.tobaccoleaf.org>. Acesso em: jan.2011.

LOPES FILHO, Boanerges B. et al. Transdisciplinaridade, metáforas e comunicação organizacional: reflexões sobre transformações mercadológicas, terminológicas e identitárias. In: XV CONGRESSO DE CIÊNCIAS DA COMUNICAÇÃO NA REGIÃO SUDESTE, XV, Vitória (ES), 2010. Anais...São Paulo: Intercom, 2010.

LUCK, Steve. The complete guide to cigars. Bath: Parragon, 2008.

OLIVEIRA, Ivone de Lourdes; PAULA, Carine F. Caetano de. Comunicação no contexto das organizações: produtora ou ordenadora de sentidos. In: OLIVEIRA, Ivone de Lourdes; SOARES, Ana Thereza Nogueira (Org.). Interfaces e tendências da comunicação. São Caetano do Sul (SP): Difusão, 2008.

SARDINHA, Tony Berber. Metáfora. São Paulo: Parábola Editorial, 2007.

VIZEU, Alfredo. O lado oculto do telejornalismo. Florianópolis: Calandra, 2005.

Recebido em: 19.03.2012 / Aceito em: 15.06.2012 